\title{
Pancreatic duct abnormalities in gall stone disease: an endoscopic retrograde cholangiopancreatographic study
}

\author{
S P Misra, P Gulati, V Choudhary, B S Anand
}

\begin{abstract}
This study was carried out to assess pancreatic duct abnormalities in gall stone disease. Endoscopic retrograde cholangiopancreatograms of 50 patients with gall stone disease were analysed and the results compared with those obtained in 33 patients investigated for cholestatic jaundice who were found to have a normal biliary tree (control group). Abnormal pancreatograms were obtained in $24(48 \%)$ patients with gall stone disease and in only two $(6 \%)$ in the control group; the differences were statistically significant $\left(\chi^{2}=14.3 ; p<0.001\right)$. The patients in the control group showed mild abnormalities as did those in the gall stone group. The frequency of various abnormalities were: mild $16(32 \%)$, moderate five $(10 \%)$, and severe three (6\%). Pancreatic duct abnormalities were more severe and occurred more frequently in patients with gall stones who had stones in the biliary tree than in patients with a normal biliary tree (postcholecystectomy patients, $55 \% \quad v 25 \%$ ) but the difference between the two groups just failed to be significant $\left(\chi^{2}=3.34\right)$. In conclusion, nearly half of all patients with gall stone disease have pancreatic duct abnormalities and in $16 \%$ these were severe enough to be labelled as chronic pancreatitis.
\end{abstract}

It is well established that gall stone disease is associated with the development of acute pancreatitis. $^{1-10}$ The role of gall stones in the pathogenesis of chronic pancreatitis is, however, controversial and although some workers have reported such an association," definite proof in its favour is lacking. ${ }^{12}{ }^{13}$ In previous studies, endoscopic retrograde cholangiopancreatograms (ERCPs) have shown abnormalities of the pancreatic duct system in a large proportion of patients with gall stone disease. ${ }^{14}$ is These studies, however, had the disadvantage that the role of other factors which adversely affect the pancreatic duct, such as aging and alcohol, had not been properly evaluated. The present study was therefore carried out to properly assess the anatomy of the pancreatic ducts in otherwise healthy non-alcoholic patients with gall stone disease.

\section{Methods}

Analysis of 1307 ERCP examinations performed over three and a half years from January 1985 to June 1988 was carried out and the following two groups were selected. Group I $(n=33)$ comprised patients who were investigated for the assess- ment of cholestatic jaundice of viral hepatitis and were found to have a normal biliary tree. Group II $(n=50)$ comprised non-alcoholic patients suffering from gall stone disease; some of these patients showed stones in the biliary tree $(n=38)$ while others with postcholecystectomy symptoms were found to have a normal examination $(n=12)$; the latter were all confirmed cases of gall bladder stones for which a cholecystectomy had been carried out in the past. There was no clinical feature suggestive of chronic pancreatitis or carcinoma of the pancreas in these patients and ultrasound examination did not show calcification or a mass lesion in the pancreas. None of the patients had had acute pancreatitis in the past. Patients with gall stone disease were referred to us because of jaundice, biliary pain, cholangitis, or retained stones. None of the postcholecystectomy patients had undergone common bile duct exploration at surgery.

The essential criterion for selection for the study was clear delineation of the entire main pancreatic duct up to the tail along with the first and second order side branches but without acinar filling. Measurements of the main pancreatic duct in patients showing a completely blocked duct were not included for analysis. The ERCP films were assessed independently by two observers. The length and width of the main pancreatic duct was measured by calipers and the mean of the two readings was taken for final analysis. ${ }^{16}$ To avoid personal bias neither observer was informed of the clinical details of the patients and, moreover, the biliary tree was concealed by means of thick black cardboard. The configuration of the pancreatograms was categorised according to the Cambridge classification ${ }^{17}$ with minor modifications into one of the following: normal=entirely normal main pancreatic duct and $<3$ ectasias of the side branches; mild=mild irregularity in the contour of the main pancreatic duct or ectasia of $>3$ of the side branches; moderate $=$ areas of narrowing of the main pancreatic duct; severe $=$ one or more of the following: strictures, complete obstruction, filling defects, and cystic dilatation of the main pancreatic duct. The magnification factor was accounted for by measuring the width of the

TABLE I Age and sex distribution of the two groups

\begin{tabular}{llll}
\hline & $\begin{array}{l}\text { Control subjects } \\
(n=33)\end{array}$ & $\begin{array}{l}\text { Patients with gall } \\
\text { stone disease }(n=50)\end{array}$ & $p$ \\
\hline Age (years) & $38(9 \cdot 6)$ & $42 \cdot 3(13 \cdot 1)$ & NS \\
Mean (SD) & $19-65$ & $21-70$ & $<0.01$ \\
Range & $16 / 17$ & $9 / 41$ & \\
Sex $($ M/F) & & & \\
\hline
\end{tabular}

NS $=$ not significant
Correspondence Gastroenterology Unit Postgraduate Department of Medicine, MLN Medical India.

Accepted for publication 20 November 1989 
TABLE II Characteristics of the pancreatic duct in the two groups

\begin{tabular}{|c|c|c|c|}
\hline $\begin{array}{l}\text { Main pancreatic } \\
\text { duct }\end{array}$ & $\begin{array}{l}\text { Control subjects } \\
(n=33)\end{array}$ & $\begin{array}{l}\text { Patients with gall } \\
\text { stone disease }(n=50)\end{array}$ & $p$ \\
\hline $\begin{array}{l}\text { Length }(\mathrm{cm}): \\
\text { Mean }(\mathrm{SD}) \\
\text { Range }\end{array}$ & $\begin{array}{l}16 \cdot 1(2 \cdot 3) \\
10 \cdot 6-21 \cdot 1\end{array}$ & $\begin{array}{l}15 \cdot 9(2 \cdot 1) \\
11 \cdot 5-20 \cdot 6\end{array}$ & NS \\
\hline $\begin{array}{l}\text { Width }(m m): \\
\text { Head }\end{array}$ & & & \\
\hline $\begin{array}{c}\text { Mean }(\mathrm{SD}) \\
\text { Range } \\
\text { Body }(\mathrm{mm})\end{array}$ & $\begin{array}{l}3 \cdot 6(0 \cdot 90) \\
1 \cdot 7-6 \cdot 5\end{array}$ & $\begin{array}{l}3 \cdot 7(1 \cdot 1) \\
1 \cdot 7-6 \cdot 7\end{array}$ & NS \\
\hline $\begin{array}{l}\text { Mean (SD) } \\
\text { Range }\end{array}$ & $\begin{array}{l}2 \cdot 5(0 \cdot 7) \\
1 \cdot 3-4 \cdot 5\end{array}$ & $\begin{array}{l}2 \cdot 4(0 \cdot 8) \\
1 \cdot 5-4 \cdot 1\end{array}$ & NS \\
\hline $\begin{array}{l}\text { Tail } \\
\text { Mean (SD) } \\
\text { Range }\end{array}$ & $\begin{array}{l}1 \cdot 3(0 \cdot 4) \\
0 \cdot 8-2 \cdot 3\end{array}$ & $\begin{array}{l}1.4(0.4) \\
0.8-2 \cdot 8\end{array}$ & NS \\
\hline
\end{tabular}

NS $=$ not significant

endoscope in the duodenum and making the adjustments as described previously. ${ }^{18}$

STATISTICS

Statistical analysis was done using Student's $t$ test and the $\chi^{2}$ test with or without Yates's correction as appropriate.

\section{Results}

The age and sex ratio of control subjects and patients with gall stone disease are shown in Table I. There was no difference between the two groups with regard to the age distribution but there were significantly more women in the gall stone group than in the control group $(82 \% v$ $\left.54 \cdot 5 \% ; \chi^{2}=7 \cdot 2 ; p<0 \cdot 01\right)$

The dimensions of the pancreatic duct are shown in Table II. There was no difference in the length of the main pancreatic duct between the two groups. Similarly, the width of the head, body, and tail of the duct was similar in the two groups. To assess the effect of aging, the patients were divided into two groups of under 40 years and 40 and over. In patients with gall stone disease, the mean (SD) width of the duct head $(4(1 \cdot 1) \mathrm{mm})$ was significantly greater in patients over 40 than in those under $40(3.3$ (1) $\mathrm{mm}$; $\mathrm{p}<0.05)$. Differences in the body and tail were not significant.

The analysis of pancreatic duct configuration is shown in Table III. Only two $(6 \%)$ of 33 control subjects showed abnormalities of the pancreatic duct compared to 24 of $50(48 \%)$ patients with gall stone disease; the difference was highly significant $\left(\chi^{2}\right.$ with Yates's correction $=14.3 ; \mathrm{p}<0.001)$. The two control subjects showed only mild abnormalities. In patients with gall stone disease the majority $(16 ; 32 \%)$ showed

TABLE III Pancreatic duct morphology in the two groups. (Percentages in parentheses)

\begin{tabular}{|c|c|c|c|c|}
\hline \multirow[b]{2}{*}{ Pancreatogram } & \multirow{2}{*}{$\begin{array}{l}\text { Control } \\
\text { subjects } \\
(n=33)\end{array}$} & \multicolumn{3}{|c|}{ Patients with gall stone disease } \\
\hline & & $\begin{array}{l}\text { Stones present } \\
(n=38)\end{array}$ & $\begin{array}{l}\text { No stone } \\
(n=12)\end{array}$ & $\begin{array}{l}\text { Combined } \\
(n=50)\end{array}$ \\
\hline $\begin{array}{l}\text { Normal } \\
\text { Abnormal } \\
\text { Mild } \\
\text { Moderate } \\
\text { Severe }\end{array}$ & $\begin{array}{l}31(94) \\
2(6) \\
2(6) \\
0 \\
0\end{array}$ & $\begin{array}{c}17(45) \\
21(55) \\
13(34) \\
5(13) \\
3(8)\end{array}$ & $\begin{array}{l}9(75) \\
3(25) \\
3(25) \\
0 \\
0\end{array}$ & $\begin{array}{c}26(52) \\
24(48) \\
16(32) \\
5(10) \\
3(6)\end{array}$ \\
\hline
\end{tabular}

The incidence of pancreatic ductular abnormalities in patients with gall stones was significantly higher than in the control group $\left(\chi^{2}=14.3 ; p<0.001\right)$.

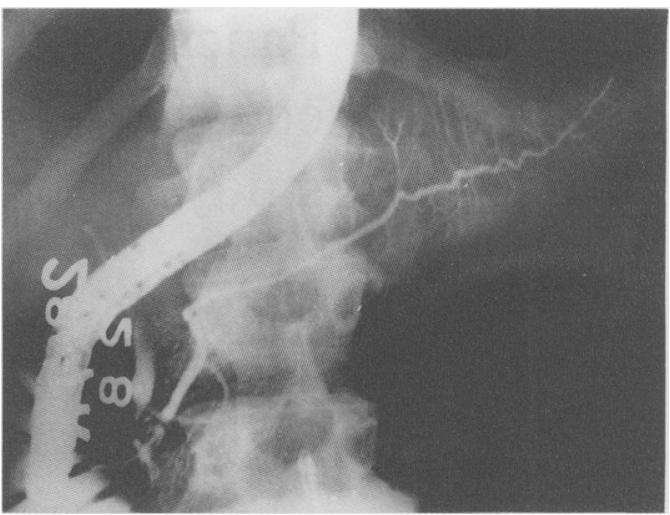

Figure 1: Mild irregularity in the main pancreatic duct in a patient with gall stone disease. The side branches are also showing mild ectasia.

mild abnormalities (Fig 1). A moderate degree of abnormality was seen in five $(10 \%)$ and the remaining three $(6 \%)$ showed severe changes (Fig 2). Patients with gall stones in the biliary tree shown by ERCP had a higher incidence of an abnormal pancreatic duct $(21$ of $38,55 \%)$ than those with a normal biliary tree (postcholecystectomy group; three of $12 ; 25 \%)$; the difference just failed to be significant $\left(\chi^{2}=3 \cdot 34\right)$. Moreover, all these patients showed mild abnormalities, while in the group with gall stones eight of 38 (21\%) had moderate to severe changes.

The effect of age on pancreatic duct abnormalities is shown in Table IV. There was no difference in the incidence of a normal pancreatic duct or varying degrees of duct abnormalities in patients under 40 compared to those over 40 .

\section{Discussion}

In the present study 24 ( $48 \%$ ) of 50 patients with gall stone disease showed abnormalities of the pancreatic duct compared to only $6 \%$ (two of 33 ) in the control group; the difference was highly significant $\left(\chi^{2}\right.$ with Yates's correction $=14 \cdot 3$; $\mathrm{p}<0.001$ ). These findings are similar to those obtained by Axon et al. ${ }^{15}$

To establish the pathogenesis of these abnormalities, we carefully inquired about the history of alcohol intake in all patients with gall stone disease and included in the study only those who abstained completely, which excluded even

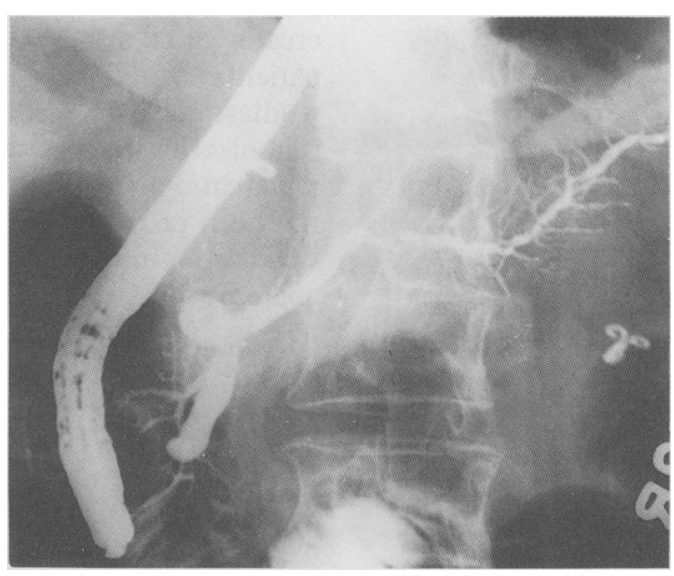

Figure 2: Severe abnormalities in a patient with gall stone disease. There are multiple strictures and areas of dilatation of the main pancreatic duct. 
TABLE IV Pancreatic duct morphology according to age in patients with gall stone disease.

\begin{tabular}{llll}
\hline & & \multicolumn{2}{l}{ No(\%) with abnormal pancreatic ducts } \\
\cline { 3 - 4 } $\begin{array}{l}\text { Age }(\%) \text { with } \\
\text { (years) }\end{array}$ & $\begin{array}{l}\text { normal pancreatic } \\
\text { ducts }\end{array}$ & Mild & $\begin{array}{l}\text { Moderate and } \\
\text { severe }\end{array}$ \\
\hline$<40$ & $11(22)$ & $7(14)$ & $4(8)$ \\
$\geqslant 40$ & $15(30)$ & $9(18)$ & $4(8)$
\end{tabular}

There was no significant difference in the incidence of abnormal pancreatic ducts in relation to the age of the patient.

social drinkers. Another possible incriminating factor was the influence of aging. SchmitzMoormann et al noted mild abnormalities of the pancreatic duct in $25 \%$ of normal people over 45. ${ }^{19}$ Similarly, in a report from Japan, pancreatic duct abnormalities and even calculi were seen in older subjects who were otherwise completely heathy; the prevalence of pancreatic calculi increased from $0 \%$ in those under 65 years of age to $4 \cdot 2 \%$ in those aged $70-79$ to over $16 \%$ in those in their nineties. ${ }^{20}$ In the present study the effect of age was examined in two ways. Firstly, only two (6\%) subjects in the control group, which had a similar age distribution to the group with gall stone disease (mean (SD) $38(9 \cdot 6) v 42 \cdot 3$ $(13 \cdot 1)$ years) showed pancreatic duct abnormalities. Secondly, in the group with gall stone disease the pancreatograms of patients aged under 40 were compared to those who were 40 and over. There was no significant difference in the incidence of pancreatic duct abnormalities in the younger $(11 ; 22 \%)$ compared to the older patients $(13 ; 26 \%)$. Indeed, the only effect of aging was dilatation of the head of the main pancreatic duct. Similar findings of an increase in the width of the pancreatic duct with increasing age were observed in our earlier study on pancreatograms obtained in normal people. ${ }^{16}$

In the absence of other factors the pathogenesis of the pancreatic duct abnormalities can be attributed directly to the associated gall stone disease. The possibility arises that the pancreatic duct gets damaged when a gall stone passes through the ampulla of Vater. It is well established that acute pancreatitis can occur in such a setting, ${ }^{1-10}$ and the duct abnormalities appear to be the structural counterpart of the acute inflammatory process. In support of this hypothesis is the study of Hamilton et al who observed an abnormal pancreatogram at ERCP in eight (40\%) of 20 patients presenting with acute pancreatitis. ${ }^{21}$ Furthermore, it has been observed that after an episode of acute pancreatitis, pseudopancreatic cysts can press on the main duct and produce a localised area(s) of narrowing. Thus, alterations in the contour of the pancreatic duct with areas of strictures and dilatation may be the consequence of an acute insult.

The clinical importance of these abnormalities is of much interest and raises the question of whether these abnormalities eventually result in the development of chronic pancreatitis. Though the incidence of chronic pancreatitis in this part of India is not known, it appears to be a fairly common disease..$^{22}$ Similarly, the incidence of gall stone disease is not known, but a necropsy study noted the prevalence to be $5 \cdot 4 \% .^{23}$ Obstructive jaundice and the presence of gall stones in the common bile duct have been observed in chronic pancreatitis, but these are usually secondary to the compression of the intrapancreatic portion of the common bile duct by a fibrotic pancreas, ${ }^{13}$ and most experts do not believe that gall stones have a role in the pathogenesis of chronic pancreatitis. ${ }^{12} 13$ On the basis of these observations we believe that clincally important chronic pancreatitis is unlikely to occur in these patients, although the subsequent cause of the abnormalities - whether they worsen or show recovery - can only be judged with longterm follow up.

It is concluded that about half of the patients with gall stone disease showed abnormalities of the pancreatic duct and in $16 \%$ the alterations were severe enough for a diagnosis of chronic pancreatitis to be made. The longterm importance of these abnormalities is not clear.

1 Glenn F, Frey C. Re-evaluation of the treatment of pancreatitis associated with biliary tract disease. Ann Surg 1964; 160: 723-36.

2 Dixon JA, Hillam JD. Surgical treatment of biliary tract disease associated with acute pancreatitis. Am $\mathcal{F}$ Surg 1970; 120: $371-5$.

3 Acosta JM, Ledesma CL. Gallstone migration as a cause of acute pancreatitis. N Engl F Med 1974; 290: 484-7.

4 Kelly TR. Gallstone pancreatitis: pathophysiology. Surgery 1976; 80: 488-92.

5 Imrie W, Whyte AS. A prospective study of acute pancreatitis.

Brf Surg 1975; 62: 490-4.
6 Freund H, Pfeffermann R, Durst AL, Rabinovici N. Gallstone pancreatitis. Exploration of the biliary system in acute and recurrent pancreatitis. Arch Surg 1976; 111: 1106-7.

7 Ong GB, Lam KH, Lam SK, et al. Acute pancreatitis in Hong-Kong. Brf Surg 1979; 66: 398-403.

8 Ranson JHC. The timing of biliary surgery in acute pancreatitis. Ann Surg 1979; 189: 654-63.

9 Kelly TR, Swaney PE. Gallstone pancreatitis: the second time around. Surgery 1982; 92: 571-5.

10 Jones BA, Salsberg BB, Bohnen JMA, Mehta MH. Common pancreaticobiliary channels and their relationship to gallstone size in gallstone pancreatitis. Ann Surg 1987; 205: 123-8.

11 Geevarghese PJ. Calcific pancreatitis: causes and mechanisms in the tropics compared with those in the subtropics. Trivandrum: the tropics compared with those in
St Joseph's Press, 1986: 6-12.

12 Grendell JH, Cello JR. In: Sleisenger MH, Fordtran JS, eds. Gastrointestinal diseases: pathophysiology, diagnosis, management. 3rd ed. Philadelphia: Saunders, 1983: 1485-514.

13 Bank S. Chronic pancreatitis: clinical features and medical management. Am f Gastroenterol 1986; 81: 153-67.

14 Satake K, Umeyama K, Kobayashi K, et al. An evaluation of endoscopic pancreaticocholangiography in surgical patients. Surg Gynecol Obstet 1975; 140: 349-54.

15 Axon ATR, Ashton MG, Lintott DJ. Pancreatogram changes in patients with calculous biliary disease. Brf Surg 1979; 66: 466-70.

16 Anand BS, Vij JC, Mac HS, Choudhary V, Kumar A. Effect of aging on the pancreatic duct: a study based on endoscopic retrograde pancreatography. Gastrointest Endosc (in press).

17 Axon ATR, Classen M, Cotton PB, Cremer M, Freeny PC Lee WR. Pancreatography in chronic pancreatitis: interLee WR. Pancreatography in chronic pan
national definition. Gut 1984; 25: 1107-12.

18 Misra SP, Gulati P, Thorat VK, Vij JC, Anand BS Pancreaticobiliary ductal union in biliary diseases: an endoscopic retrograde cholangiopancreatographic study Gastroenterology 1989; 96: 907-12.

19 Schmitz-Moormann P, Riedel R, Ihm P. Morphometrische Untersuchungen der Kaliberschewankungen an normalen Duetu pancreaticus major. Z Gastroenterol 1981; 19: 299306.

20 Nagai H, Ohtsubo K. Pancreatic lithiasis in the aged. Gastroenterology 1984; 86: 331-8.

21 Hamilton I, Bradley P, Lintott DJ, McMohan MJ, Axon ATR. Endoscopic retrograde cholangiopancreatography in the investigation and management of patients after acute the investigation and management of

22 Tandon R, Rai RR, Nundy S, Vashist S. A study of chronic pancreatitis at the All India Institute of Medical Sciences, pancreatitis at the All India Institute of Medical Sciences, New Delhi. In: Balakrishnan, ed. Chronic pancrea
India. Trivandrum: St Joseph's Press, 1987: 9-14.

23 Chuttani PN. Cholelithiasis in India. Proceedings of 3rd World Congresses of Gastroenterology. Basel: Karger, 1966: 163. 